\title{
NSCLC as a chaperonopathology: diagnostic and prognostic significance of HSPB5
}

\author{
D Petrov ${ }^{1 *}$, R Cherneva ${ }^{2}$, G Yankov $^{1}$, D Marinova $^{2}$ \\ From 23rd World Congress of the World Society of Cardio-Thoracic Surgeons \\ Split, Croatia. 12-15 September 2013
}

\section{Background}

Chaperones are essential in carcinogenesis and their non-invasive measurement in peripheral blood of cancer patients is useful for diagnostic and prognostic purposes.

The aim of our study was to determine the role of chaperone HspB5 in tumor biology and assess its significance for NSCLC diagnosis and prognosis.

\section{Methods}

ELISA was applied to determine the plasma levels of HspB5 in 45 patients, operated on for NSCLC, 38 high risk COPD patients and 45 age and sex-matched healthy volunteers. The pTNM of NSCLC patients was defined according to the 7th revision of TNM staging system. All operated on patients were followed up either their death or up to 5 years. ROC analysis was used to characterize the diagnostic role of HspB5. The one and fiveyear survival rates were defined by Kaplan-Maier.

\section{Results}

Fifteen patients were stage I (IA-5; IB-10), 15 - stage II (IIB-15) and 15 - stage IIIA. HspB5 correlated positively to the local invasion - $\mathrm{T}$ factor progression ( $\mathrm{T} 1 \mathrm{~b}-0.309$, $\mathrm{T} 2 \mathrm{a}-0.438$, T2b-0.526 T3 - 0.620, p-0.043). It was useful in distinguishing patients with and without lymphogenic spread (N0-0.369; N1-3-0.523, p-0.045). Its plasma levels could discern NSCLC patients (OD-0.413) among high risk COPD patients (0.364) and healthy volunteers $(0.276, \mathrm{p}-0.001)$. ROC analysis defined specificity of $72 \%$ and sensitivity of $62 \%$ at a cut-off 0.317 . Neither one, nor five-year survival rates were associated with HspB5 plasma levels (log rank p-0.624)

\footnotetext{
* Correspondence: danail_petrov@hotmail.com

'Thoracic Surgery, Saint Sophia University Hospital for Pulmonary Diseases, Medical University, Sofia, Bulgaria

Full list of author information is available at the end of the article
}

\section{Conclusion}

HspB5 is positively associated with the local invasion and lymphogenic spread. It may find application in the diagnosis of NSCLC patients, but has no prognostic significance.

\section{Authors' details \\ ${ }^{1}$ Thoracic Surgery, Saint Sophia University Hospital for Pulmonary Diseases, Medical University, Sofia, Bulgaria. ${ }^{2}$ Pneumology, Alexandrovska University} Hospital, Medical University, Sofia, Bulgaria.

Published: 11 September 2013

\section{doi:10.1186/1749-8090-8-S1-O230}

Cite this article as: Petrov et al:: NSCLC as a chaperonopathology: diagnostic and prognostic significance of HSPB5. Journal of

Cardiothoracic Surgery 2013 8(Suppl 1):O230.
Submit your next manuscript to BioMed Central and take full advantage of:

- Convenient online submission

- Thorough peer review

- No space constraints or color figure charges

- Immediate publication on acceptance

- Inclusion in PubMed, CAS, Scopus and Google Scholar

- Research which is freely available for redistribution
C Biomed Central

\section{() Biomed Central}

